\title{
MabCent: Arctic marine bioprospecting in Norway
}

\author{
Johan Svenson
}

Received: 8 November 2011/Accepted: 12 May 2012/Published online: 30 May 2012

(C) The Author(s) 2012. This article is published with open access at Springerlink.com

\begin{abstract}
The deep waters surrounding the coastline of the northern parts of Norway represent an exciting biotope for marine exploration. Dark and cold Arctic water generates a hostile environment where the ability to adapt is crucial to survival. These waters are nonetheless bountiful and a diverse plethora of marine organisms thrive in these extreme conditions, many with the help of specialised chemical compounds. In comparison to warmer, perhaps more inviting shallower tropical waters, the Arctic region has not been as thoroughly investigated. MabCent is a Norwegian initiative based in Troms $\varnothing$ that aims to change this. Since 2007, scientists within MabCent have focussed their efforts on the study of marine organisms inhabiting the Arctic waters with the long term goal of novel drug discovery and development. The activities of MabCent are diverse and range from sampling the Arctic ice shelf to the chemical synthesis of promising secondary metabolites discovered during the screening process. The current review will present the MabCent pipeline from isolation to identification of new bioactive marine compounds via an extensive screening process. An overview of the main activities will be given with particular focus on isolation strategies, bioactivity screening and structure
\end{abstract}

J. Svenson ( $\bowtie)$

SmallStruct, Department of Chemistry, University

of Troms $\varnothing$, Breivika, 9037 Troms $\varnothing$, Norway

e-mail: johan.svenson@uit.no determination. Pitfalls, hard earned lessons and the results so far are also discussed.

Keywords Pharmacognosy · Arctic - Cold adaption · Psychrophile - Screening - Bioprospecting · Norway · MabCent

\section{Introduction}

With one of the longest coastlines in the world it is not surprising that Norway is a country with a rich history in both marine exploration and exploitation. The discovery of massive oil and gas deposits in the late 1960s had a huge impact, rapidly transforming a humble nation dependent on fishing and shipping to a very wealthy country. The initial discoveries were made in the North Sea and have been followed by significant finds in the Barents Sea making Norway a developed country with a high standard of living. Being well aware of the fact that a national economy based on the petroleum industry is not long term viable the government is now attempting to convert some of its revenue into sustainable industries capable of excelling in the post-petroleum era. As a result, several initiatives to generate internationally competitive Centres for Research based Innovation (CRI) have been launched by the Norwegian research council since 2007. Furthermore, in 2009, the Norwegian government launched a national strategy entitled 
Fig. 1 Examples of highly potent marine compounds currently undergoing clinical trials. The challenging macrocyclic lactone bryostatin-1 (1) with its 11 stereocentres was only recently prepared synthetically (Keck et al. 2011). The unusual $\beta$ lactone salinosporamide A isolated from the halophilic actinomycete Salinispora (2) is a potent orally active proteasome inhibitor (Chauhan et al. 2005)

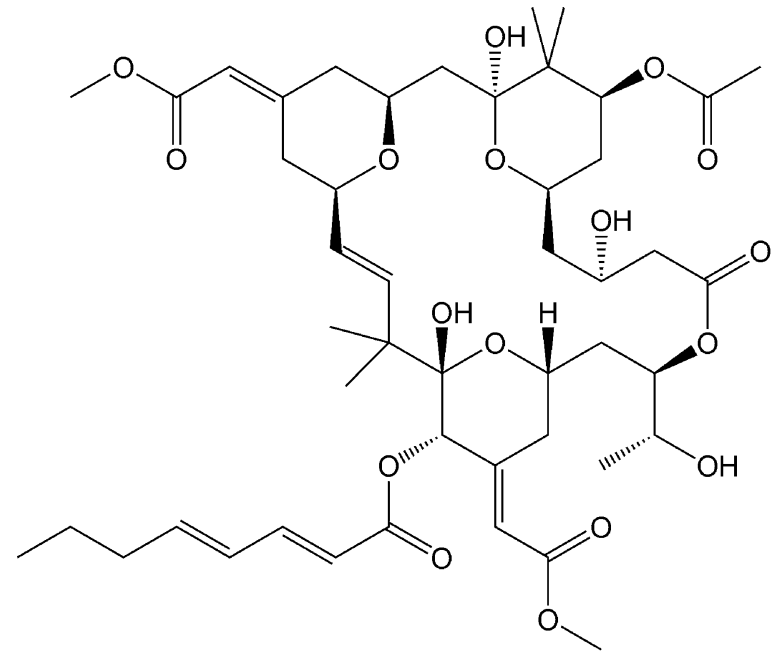

1

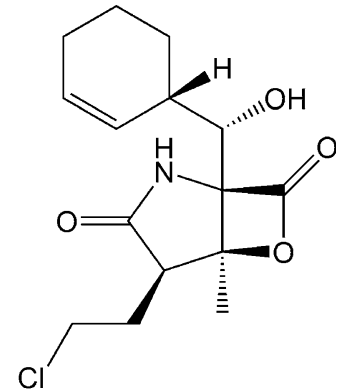

2
"Marine bioprospecting-a source of new and viable wealth creation", providing funding for a national infrastructure and research within marine natural products and drug discovery.

Norwegian scientists are for this reason once more turning to the ocean for inspiration. The deep fjords and the open oceans surrounding the Norwegian mainland are cold and dark and organisms willing to survive here must adapt to the extreme conditions. They do so by producing a range of secondary metabolites and specialised proteins providing them with advantages and protection against predation and microbial intruders (Kubanek et al. 2003; Matz et al. 2008). Such compounds have been chemically optimised during millions of years of evolution and represent entities with significant potential for several industrial and medical applications (Molinski et al. 2009; Mayer et al. 2010). Nearly two thirds of the commercial pharmaceuticals originate from natural products (Cragg et al. 2009). There is a precedence for marine metabolites as approved therapeutics. Ziconotide (Prialt ${ }^{\circledR}$ ) is a synthetic analogue of a naturally occurring 25-amino acid peptide, $\omega$-Conotoxin MVIIA, which is isolated from the venom of the piscivorous cone snail Conus magus (Olivera et al. 1985; Terlau and Olivera 2004). It was the first marine-derived compound approved by FDA in December 2004 as a potent analgesic (Garber 2005). Several other promising leads such as bryostatin-1 (compound 1 in Fig. 1) from Bugula neritina (Pettit et al. 1982) with subnanomolar binding to protein kinase $\mathrm{C}$ as well as numerous other biological activities (Mutter and Wills 2000) and salinosporamide $\mathrm{A}$, active against multiple myeloma (Chauhan et al. 2008; Fenical et al. 2009), shown as compound 2 in Fig. 1 are currently under development.

As of 2011, six marine derived drugs have been approved by FDA and one by the European Union. Thirteen others are in various stages of clinical trials (Mayer et al. 2010, 2011).

Despite its abundance of marine organisms, Norway has done relatively little towards studying their contents. MabCent is a Norwegian initiative headed by Professor Trond $\varnothing$. Jørgensen based in Troms $\varnothing$ that aims to change this. The centre for research based innovation has been focussed on studying Arctic marine organisms as these represent a group of organisms that have not been well studied and have the potential to display interesting biochemistries due their adaption to living conditions near, and below the freezing point of water (Fig. 2).

Easy access to organisms is a significant advantage and it is not coincidental that the MabCent endeavour is based at the University of Troms $\varnothing$ (UiT), the northernmost university in the world at $70^{\circ}$ north, some $300 \mathrm{~km}$ north of the Arctic Circle. UiT was particularly well suited for this task with all the essential competence and infrastructure (ranging from Arctic research vessels and marine biologist to structural chemists) readily available. With a gross budget of nearly 23 million Euros from the Norwegian research council over a period of 8 years and 

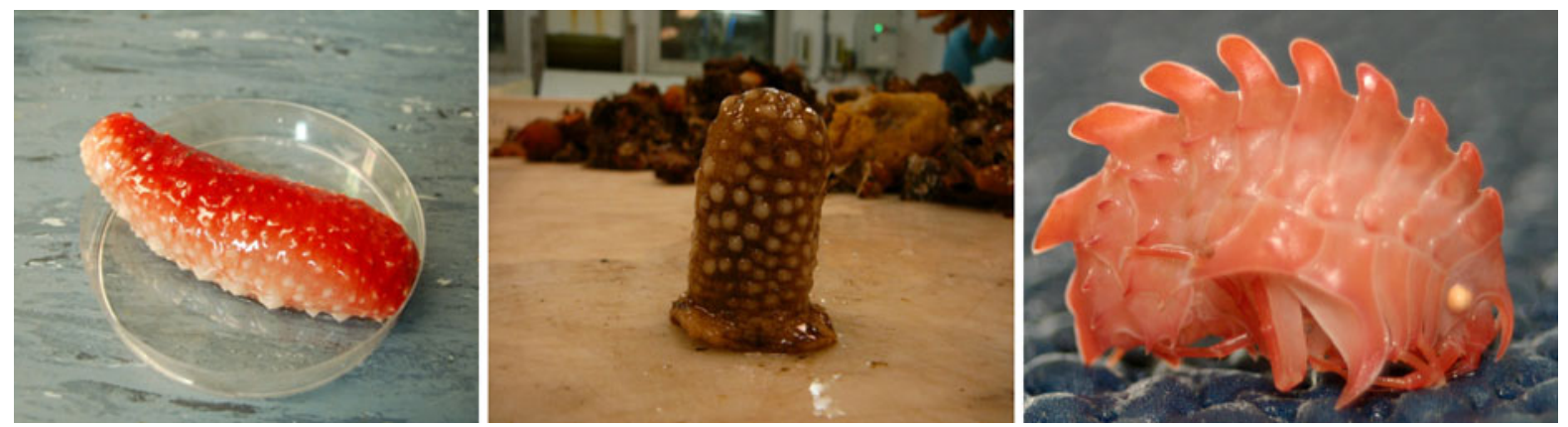

Fig. 2 The deep cold waters are rich in biodiversity and shown are three examples of diverse and colourful inhabitants. From the left Parastichopus tremulus, Hormathia nodosa and the

Table 1 Commercial partners and central platforms within the MabCent organisation

\begin{tabular}{ll}
\hline Commercial partner & Field \\
\hline $\begin{array}{l}\text { Lytix Biopharma } \\
\text { Biotec Pharmacon }\end{array}$ & $\begin{array}{l}\text { Anticancer } \\
\text { Antibacterial/Enzymes/ } \\
\text { Immunomodulation } \\
\text { Type-II Diabetes/Anti-inflammation }\end{array}$ \\
$\begin{array}{ll}\text { Pronova BioPharma } \\
\text { ABC Bioscience }\end{array}$ & Antioxidants \\
\hline Platform & Responsibility \\
\hline Marbank & Organism collection/Biobank \\
Marbio & Screening and Purification \\
NorStruct & Structure elucidation macromolecules \\
SmallStruct & Structure elucidation small molecules \\
\hline
\end{tabular}

additional financial support from UiT and commercial partners the project management have sufficient funding and time to serve its main purpose: "to find and develop high-value bioactive products for scientific and commercial exploitation by screening compounds from Arctic organisms". All the activities are based in Troms $\emptyset$ but there is also collaboration with the newly established Marine Biodiscovery Centre in Aberdeen, Scotland.

Nearly sixty staff members are associated with the MabCent activities and the centre has its own Ph.D. programme and an external scientific advisory board. In addition, four commercial partners are also participating in the research (Table 1). These partners contribute both financially and scientifically by providing key competences within their specialised field of expertise. For an annual fee the companies have the right to develop promising leads into commercial amphipode Epimeria loricata to the right. ${ }^{\odot}$ Johan Svenson \& Robert Johansen, UiT/Marbank

products according to a first right of refusal agreement. Four platforms manage the main activities and their responsibilities are listed in Table 1 .

\section{Collection}

The availability of biological material is paramount, and the cooperation with the marine biobank Marbank is therefore essential. Marbank has the national responsibility for the collection and preservation of marine resources/organisms for scientific research, commercial opportunities and exploitation purposes. Three research vessels are at Marbank's disposal and they are purposefully designed for the task. The largest one, Helmer Hanssen, at $60 \mathrm{~m}$ is a modern science platform capable of long journeys into the pack ice and capable of collecting samples in several thousand metres of water (Fig. 3). While most of the ocean waters on the globe can be regarded as dark and cold and therefore potentially rich in psychrophilic organisms, MabCent has mainly focused on Arctic waters with temperatures near or below zero degrees. The sampling stretches from the pack ice north of Svalbard, to the northern Norwegian coast line. Subzero degree water temperatures can also be found in deep water pockets in several of the fjords along the northern coastline. The material is collected during many annual excursions.

Several types of techniques are used for sample collections. Marine bacteria and microalgae are collected from both sediment and water samples using grabs and a CTD-rosette array offering enormous potential for biodiversity (Imhoff et al. 2011; Gulder 


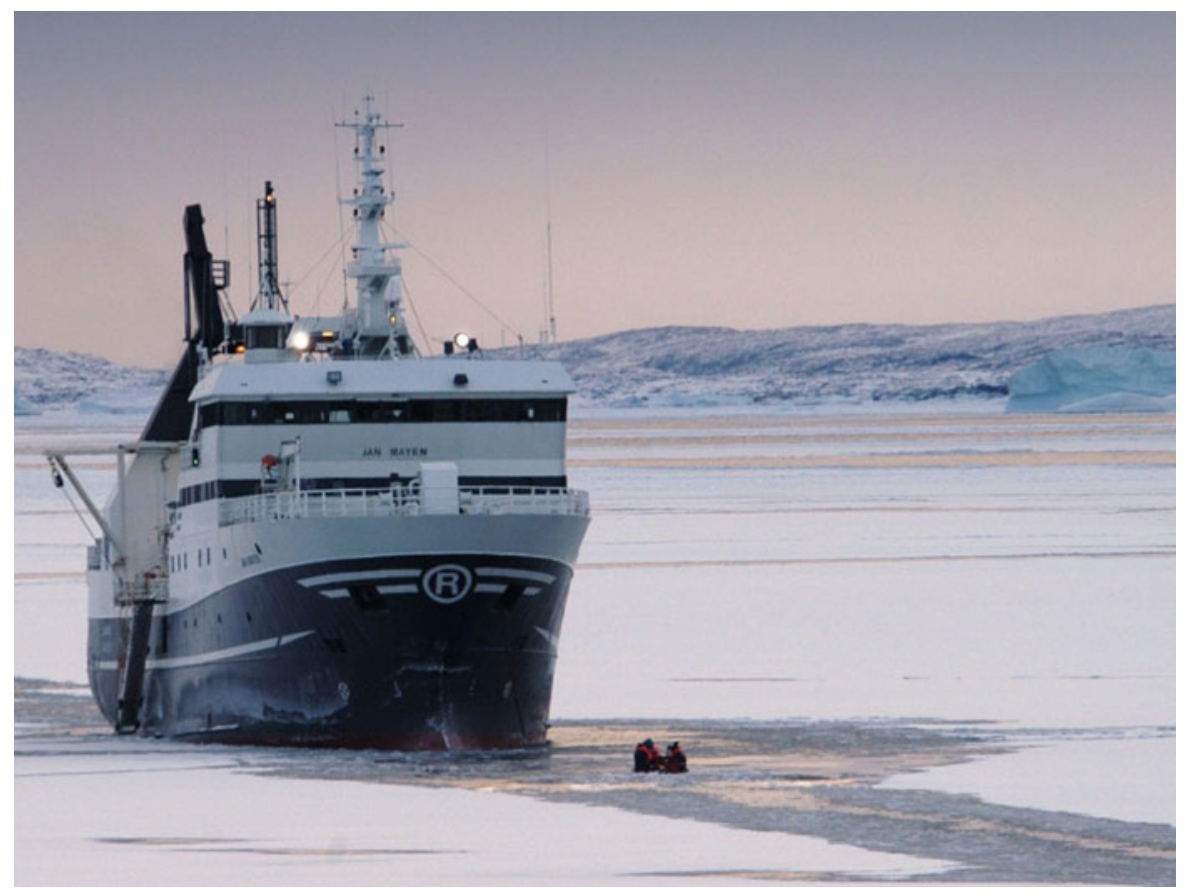

Fig. 3 Access to sturdy and modern research vessels with ice breaking capacity enables sampling in the extreme environments studied. Shown above is the 60 metre Helmer Hanssen (previously known as Jan Mayen) on a collection cruise in hostile surroundings. (C) TUNU-MAFIG, UiT

trawls. Each species is taxonomically identified and sufficient material is collected. Microbiological and genetic material from each species is also stored. Those microalgae and bacteria that can be cultivated are grown in the lab to provide enough biomass for isolation of secondary metabolites. This is the most sustainable way to get access to biological material but the generality is hampered by several factors discussed later (Fig. 4).

\section{Purification and screening}

Once the biological sample has been gathered and sorted it needs to be analysed and that is the task of Marbio. Marbio is a high-throughput analytical laboratory with access to a range of automated and manual chromatographic and spectroscopic tools as well as a range of biochemical and cellular assays. Marine metabolites can be fractionated and identified and their discrete bioactivities evaluated. Before the bioactivities can be studied, the organism is lyophilised and extracted to yield an aqueous and organic (dichloromethane:methanol) extract. At least $200 \mathrm{~g}$ of 


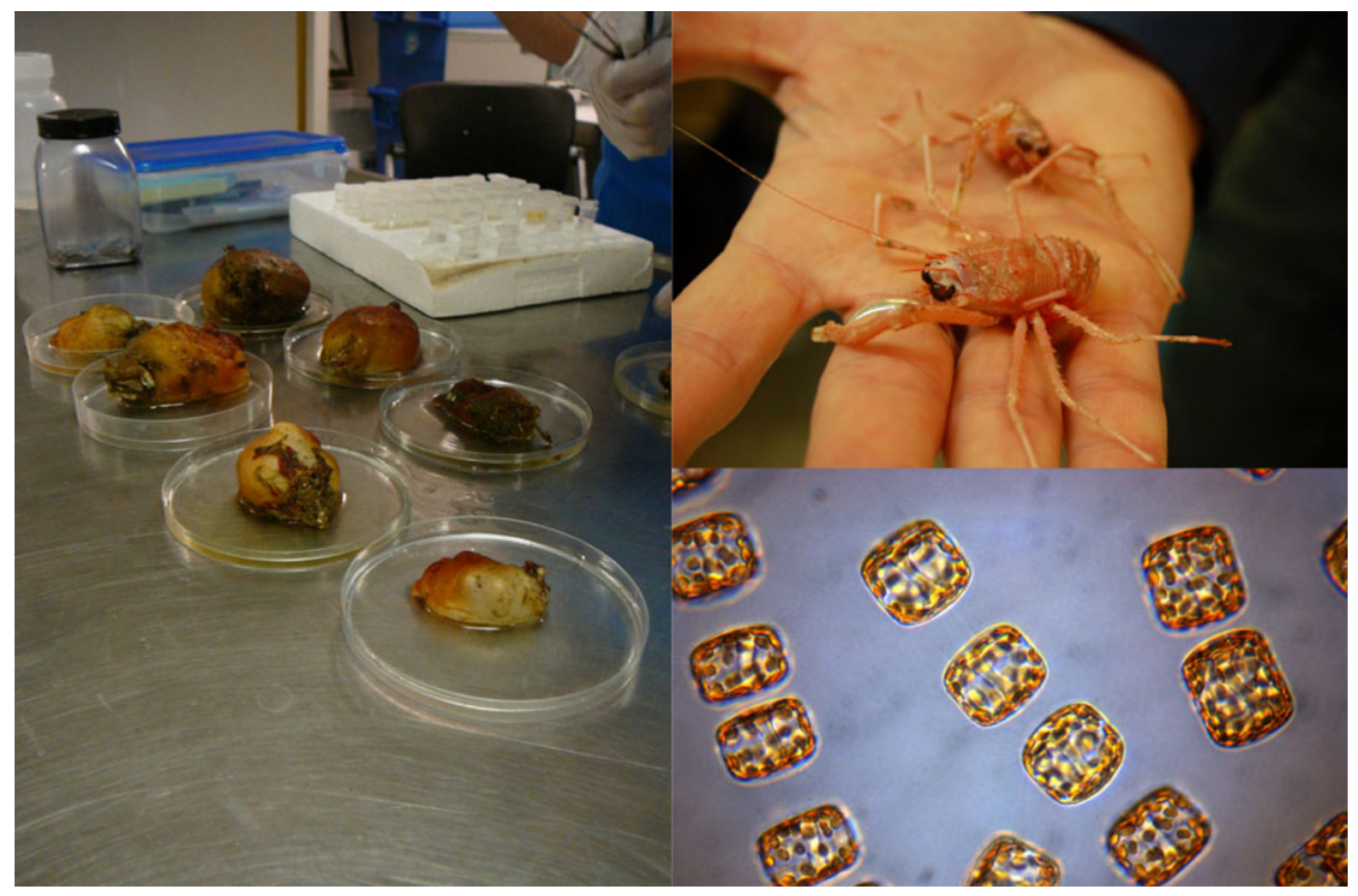

Fig. 4 DNA is collected from each collected species, both microorganisms and benthic. Shown to the right are Munida sarsi lobsters and Porosia glacialis microalgae. ${ }^{\odot}$ Johan Svenson \& Hans Christian Eilertsen, UiT

biological material is used in an attempt to generate enough pure compounds to allow for spectroscopic structural elucidation. Both the organic and aqueous fractions are analysed. Each extract is separated on a flash chromatography system packed with HP20. $1 \mathrm{~g}$ of dried extract is dry loaded and eluted at a high flow (10-12 $\mathrm{mL} / \mathrm{min}$ ) using a gradient of water, methanol and acetone and fractionated into eight fractions.

The fractions are screened in several biochemical and cellular assays shown in Table 2. Only those displaying genuine dose-response behaviour upon dilution are further considered. The assays used are based on the needs of the commercial partners and on their clinical relevance. Major disease states such as cancer, infection, life-style diseases such as obesity, metabolic syndrome, and type-II diabetes are therefore targeted in addition to a more general search for antioxidants and immunomodulating compounds.

Positive fractions (Fig. 5) are further purified by subsequent RP-HPLC separation steps to reduce the complexity of the active fraction and to pin the bioactivity to a single fraction. Once that has been achieved the task of identification ensues. While the strategy of MabCent is to look at marine organisms found in the Arctic, several of these have wider distributions. Consequently, most of the hits observed in the primary screening are caused by secondary metabolites that already have been discovered and described. Such a needle in the haystack challenge is only to be expected and identifying these known compounds as early as possible and removing them from biodiscovery pipeline is crucial. This dereplication process is on-going from the stage where the activity has been narrowed down to a single fraction.

High resolution mass spectrometry (HR-MS) analysis provides the first indication of novelty of the active compounds. The elemental composition, calculated from the accurate mass and the isotopic distribution is used to search databases such as the Dictionary of Marine Natural Products and AntiMarin before an isolation is attempted. By relying mainly on MS for the dereplication, significant time is saved as it does not require pure fractions or isolated compounds. Structural suggestions can to some extent be verified 
Table 2 MabCent screening targets

\begin{tabular}{|c|c|c|}
\hline Activity & Target & Type \\
\hline Toxicity & $\begin{array}{l}\text { MRC-5 (normal lung } \\
\text { fibroblast) }\end{array}$ & Cellular \\
\hline \multirow[t]{3}{*}{ Anticancer } & $\begin{array}{l}\text { HT-29 (colon } \\
\text { adenocarcinoma), } \\
\text { MCF-7 (breast cancer), } \\
\text { A2058 (melanoma), } \\
\text { IPC-81 (leukaemia) }\end{array}$ & Cellular \\
\hline & NF- $\kappa$ B (A549) & Cellular \\
\hline & Kinase inhibition & Biochemical \\
\hline Antibacterial & $\begin{array}{l}\text { E. coli, } S \text {. aureus, MRSA, } \\
\text { P. aeruginosa, } \\
\text { E. faecalis }\end{array}$ & Cellular \\
\hline Biofilm & S. epidermidis & Cellular \\
\hline Immunomodulation & $\begin{array}{l}\text { TNF- } \alpha, \text { IL-1 } \beta \text { (THP-1), } \\
\text { NF- } \kappa \text { B (U937) }\end{array}$ & Cellular \\
\hline \multirow[t]{2}{*}{ Diabetes } & PTB-1B & Biochemical \\
\hline & $\operatorname{PPAR} \gamma$ & Cellular \\
\hline \multirow[t]{3}{*}{ Antioxidants } & FRAP & Biochemical \\
\hline & ORAC & Biochemical \\
\hline & $\begin{array}{l}\text { Cellular Antioxidant } \\
\text { Activity }\end{array}$ & Cellular \\
\hline
\end{tabular}

using $\mathrm{MS}^{\mathrm{n}}$-fractionation experiments. Seemingly novel compounds are transferred to the structure determination platforms.

\section{Structure determination}

The two platforms devoted to structure determination are in charge of the final structural trials. Macromolecules are handled by the Norwegian centre of structural biology (NorStruct) with particular experience and expertise in handling cold-adapted proteins. Cold adaption is crucial for survival at very low temperatures and is characterised by an increased molecular flexibility to compensate for the low surrounding temperatures. Such flexibility lead to an increased catalytic efficiency and a lower thermal stability (Smalas et al. 2000). Those traits permit the cold adapted enzymes to operate efficiently at low temperatures and it also allows for a simple way of controlling their activity, making them particularly interesting for molecular biology and biotechnological applications. X-ray crystallography is routinely used in conjunction with computational chemistry to study the proteins. NorStruct have characterised and studied several novel cold adapted enzymes, some of which have been transformed into commercial biotechnological and molecular biology products such as uracilDNA glycosylase from Atlantic cod (Gadus morhua) (Leiros et al. 2003) and heat-labile shrimp alkaline phosphatase from Pandalus borealis (de Backer et al. 2002).

Smaller, more drug-like secondary metabolites that are suited for NMR analysis represent the task of SmallStruct. Access to cryoprobe fitted NMR-equipment enables analysis of the generally small sample amounts resulting from the purification and isolation processes. While the atomic connectivity of an unknown molecule is relatively easy to establish with NMR, the three-dimensional shape presents more of a problem. The low amount of pure compound often prevents the formation of crystals for X-ray analysis. Theoretical approaches in conjunction with chiroptical spectroscopic techniques, such as Raman optical activity, vibrational circular dichroism and electronic circular dichroism are therefore under development together with the Norwegian centre of theoretical and computational chemistry. This allows in-solution determination of absolute configuration in cases where $\mathrm{X}$-ray analysis is not a feasible option. This approach was recently employed to the synoxazolidinones to reveal their absolute configuration (Hopmann et al. 2012). SmallStruct is further involved in the synthetic aspects of MabCent and are performing analogue synthesis and development of the most interesting leads. The group has particular experience from the field of naturally occurring bioactive peptides and peptidomimetics (Svenson et al. 2008; Karstad et al. 2010; Flaten et al. 2011).

\section{Hits so far}

So far more than 25,000 fractions from 140 different marine organisms (mostly benthic) have been analysed and numerous bioactive marine compounds have been isolated and characterised. A schematic representation of the distribution and origin of the analysed organisms is shown in Fig. 6.

The vast majority of the compounds isolated are however already known ones and represent dereplication rather than pure discoveries as the majority of the species studied and their accompanying microflora have a large geographical distribution. Of the novel 


\section{Organic extract}

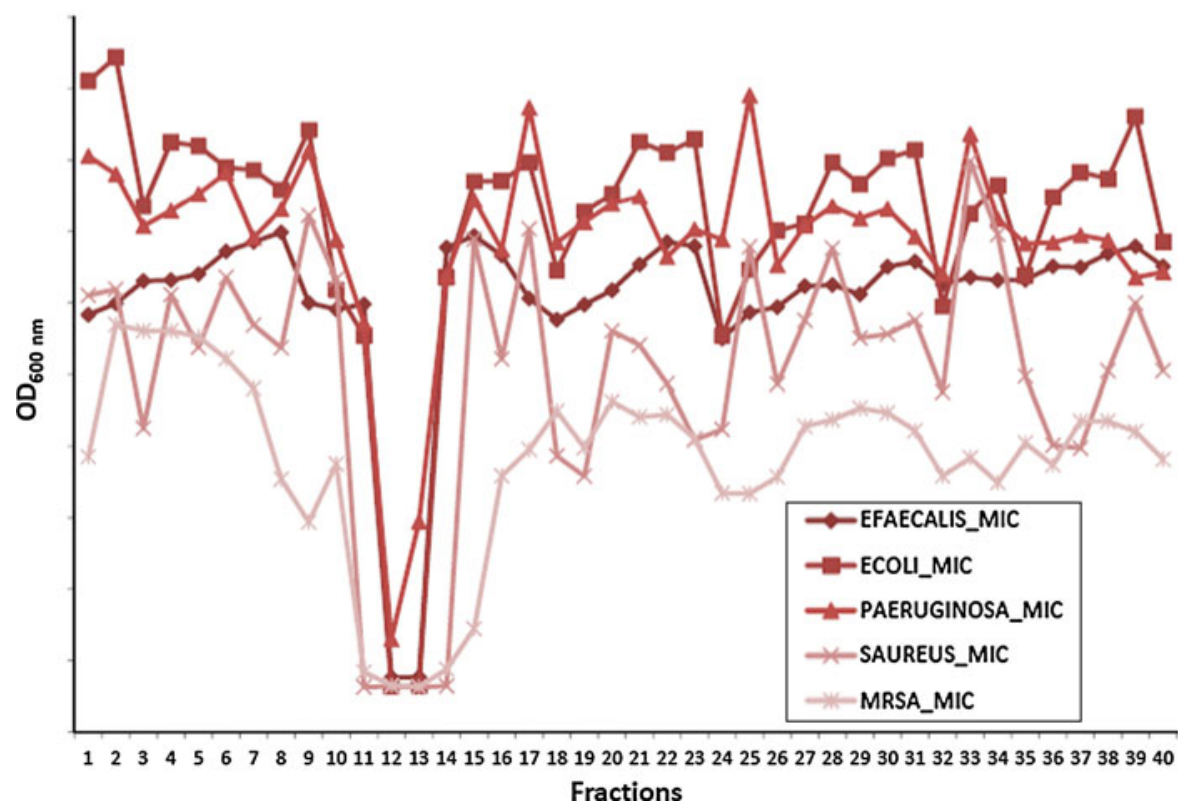

Fig. 5 Antibacterial screening of 40 fractions from a RP-HPLC purification of a marine sample extract. High activity against both Gram positive and Gram negative bacteria is observed in fractions 10-14

\section{Distribution of screened organisms}

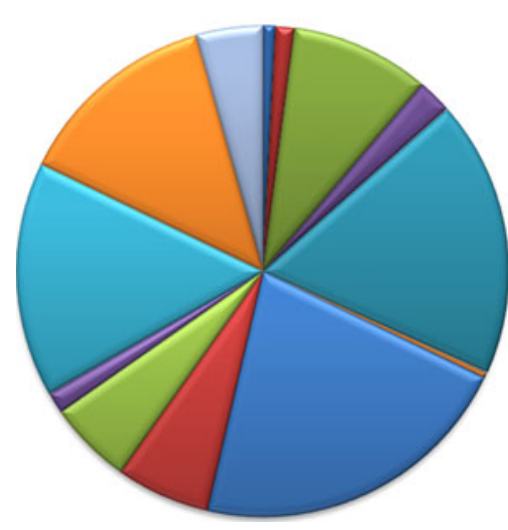

Fig. 6 Pie chart diagram over the distribution of the organisms screened by Marbio. The majority of the organisms are of benthic origin with microalgae, diatoms (Bacillariophyta) being the only class of microorganisms screened so far

compounds discovered, the antibacterial, antifungal and cytotoxic synoxazolidinone (Tadesse et al. 2010; Tadesse et al. 2011a) family stands out (Fig. 7) and they are being further developed by the commercial partner Lytix Biopharma AS.

This is a family of closely structurally related compounds that was initially isolated in surprisingly

high concentrations from the sub-Arctic ascidian Synocium pulmonaria. The synoxazolidinones contain a highly unusual heterocyclic oxazolidinone core linking two amino acid (Arg and Tyr) derivatives together. They represent only the second report of a naturally occurring 4-oxazolidinone motif with the highly antibacterial lipoxazolidinone family being the first one (Macherla et al. 2007) reported. The motif is also shared with the novel synthetic 50S ribosomal subunit binder antibiotic linezolid (Moellering 2003). It has not been established whether the biosynthetic origin of the synoxazolidinones is the ascidian itself or symbiotic microorganisms. Such brominated dipeptidic derivatives are regularly produced by marine organisms and the synoxazolidinones share structural traits with for example barettin (Lidgren and Bohlin 1986) from the cold-water sponge Geodia baretti and ianthelline (Litaudon and Guyot 1986) found in the tropical Ianthella ardis as shown in Fig. 8.

In addition, the several recently described new members of the antibacterial eusynstyelamide family also share this structural composition of halogenated hydrophobic bulk and one or two cationic groups (Tadesse et al. 2011b). A clear correlation between bioactivities and the nature of the cationic side chains 
Fig. 7 Synoxazolidinones (A-C)<smiles>COc1c(Br)cc(/C=C2\O[C@@H](C(Cl)CCNC(=N)N)NC2=O)cc1Br</smiles>

A<smiles>COc1c(Br)cc(/C=C2\O[C@@H](CCCNC(=N)N)NC2=O)cc1Br</smiles>

B<smiles>COc1c(Br)cc(/C=C2\O[C@@H]3[C@H](Cl)C[C@@H](NC(=N)N)N3C2=O)cc1Br</smiles>

C

Fig. 8 Many marine secondary metabolites are derived from heavily posttranslationally modified dipeptides and several such compounds have been identified as a result of the bio-assay guided fractionation at Marbio. Synoxazolidinone A (1), ianthelline (2) and barettin (3) are three such compounds with several chemical and structural similarities<smiles>COc1c(Br)cc(/C=C2\O[C@@H]([C@H](Cl)CCNC(=N)N)NC2=O)cc1Br</smiles><smiles>COc1c(Br)cc(C/C(=N/O)C(=O)NCCc2c[nH]c(=N)[nH]2)cc1Br</smiles><smiles>N=C(N)NCCCC1NC(=O)/C(=C/c2c[nH]c3cc(Br)ccc23)NC1=O</smiles>

3 were seen for these novel compounds (Tadesse et al. 2011b). Currently, numerous novel bioactive compounds are undergoing structural elucidation and the annual number is expected to increase the coming years due to the improved efficiency of Marbio and the introduction of both bacteria and on-site grown microalgae into the screening process. Nearly 1500 isolates of microorganisms have been collected and $16 \mathrm{~S}$ sequenced and they have yet to enter the pipeline which has so far been nearly exclusive for benthic organisms with the exception of the microalgae. The bulk of the microorganisms belong to the Proteobacteria and Bacteriodetes phyla as shown in Fig. 9. The collected microorganisms have further been taxonomically divided into 500 species and 70 different families.

\section{Discussion}

MabCent has been up and running since 2007 and will continue at least until the end of 2014 in its current form. Despite the fact the project is now on its fifth year there are still activities that can be improved and the learning curve for most involved staff has been steep and several lessons have been learnt the hard way. Initially, the progress was hindered by idiosyncratic false positives and active fractions without any apparent content. A change from an initial 40 fraction HPLC fractionation to an early flash chromatographic separation and a proper dose-response analysis of the active hits reduced those numbers to satisfactory levels. 


\section{Microorganism distribution}

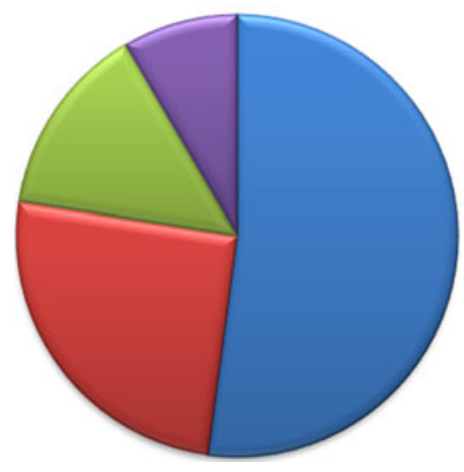

- PROTEOBACTERIA

$\square$ BACTERIODETES

$\square$ ACTINOBACTERIA

$\square$ FIRMICUTES

Fig. 9 Pie chart diagram of the phyla distribution of the microorganisms collected by Marbank

One of the most challenging issues is, despite the geographical placement of MabCent, access to sufficient amount of biological material and subsequently pure compounds. This is a universal challenge for any marine bioprospecting endeavour, perhaps best illustrated by the 18 grams of bryostatin- 1 needed for preclinical and clinical studies in 1991 which was isolated from approximately 12.6 metric tonnes of wet organism over a period of 10 months (Schaufelberger et al. 1991). Multi tonne amounts were also needed for the isolation of sufficient material of halichondrin (Hirata and Uemura 1986) and the approved antitumoral ecteinascidin 743 (Trabectidin/Yondelis ${ }^{\circledR}$ ) which had its final structural elucidation delayed by two decades due to insufficient amounts (Molinski et al. 2009). A low amount of starting material is thus an undisputed way to miss out on the most active compounds as they are by definition not needed in the same amounts as other metabolites. The antimitotic macrolide halistatin-1 for example is only present at 8.8 parts per billion in the organism (Pettit et al. 1993) illustrating that attention to the "small peaks" can be crucial. This has been obvious several times in the MabCent screening where seemingly empty HPLC fractions generate positive results in the screening assays. MS-analysis sometimes later reveals the presence of potentially novel compounds in the fractions but in no-way near high enough amounts for characterisation. The 200 grams of organism generally used by MabCent for the initial extraction may appear insufficient, but already at this stage, that minimum amount prevents analysis of numerous collected organisms. Those highly active compounds can also cause initially perplexing results upon purification of active fractions of seemingly high molecular content. For example: A $1 \mathrm{nM}$ agonist present at a $1 \%$ concentration in a mixture with $99 \%$ of another inactive compound will provide the mixture with a promising $\mathrm{IC}_{50}$ of $0.1 \mu \mathrm{M}$. The agonist itself will nevertheless most likely be regarded as noise or as "an acceptable amount" of contamination in the initial NMR analysis of the major inactive compound in that mixture thought to generate the bioactivity. Further purification removing the actual agonist will yield a pure major product with no bioactivity whatsoever in the final dose-response analysis. Such scenarios are particularly prone to appear when working with automated high-throughput techniques.

Only the most common benthic organisms and macroalgae are readily available on demand and these are also frequently the species already most thoroughly studied by others. Gathering Arctic organisms far out at sea in a dark, cold and hostile environment is not for the faint hearted and is not to be compared with a reef walk collection at low tide on a tropical coral reef. For this reason it is difficult to resample an already visited location to stock up on more of the organism if the initial results are encouraging and more material required. Seasonal variation also influences the production of secondary metabolites and it has been shown that the same species collected at the identical location a year later does not necessarily contain the same compounds (Molinski et al. 2009; Tadesse et al. 2010). So in short, one must make sure to collect as much as possible while sampling and only allow the freezer capacity on the vessel to be the limiting factor. Such an approach raises questions about sustainability (Bohlin et al. 2010) and it is clear that Nature will, only as an exception, be able to provide enough material once a commercially viable compound has been identified. If the producing organism cannot be aquafarmed, or if the compound itself cannot be synthesised, or produced by microorganisms on a large scale then one is faced with plummeting odds for success after the initial discovery.

Aware of these hurdles, MabCent has dedicated significant resources into the development of methods to grow microalgae on a large scale. The experiments have so far been successful and several species of diatoms can now be readily grown in $600 \mathrm{~L}$ incubators in high concentrations as shown in Fig. 10.

Screening of these organisms has just begun and it is realistic to expect that this strategy will generate 


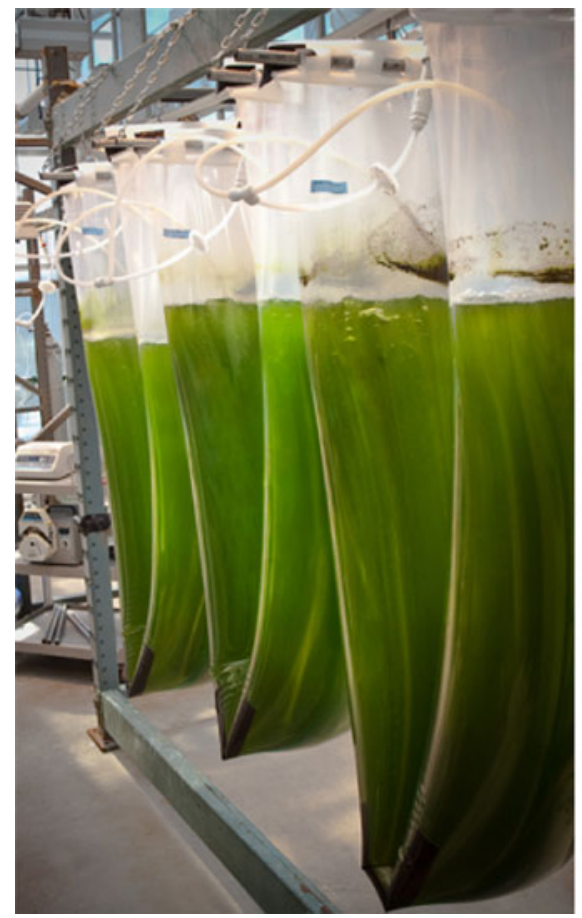

Fig. 10 Focus on organisms that can be grown in a controlled fashion is of high priority for both sustainability and practical reasons. Diatoms can for example be readily produced in both bags (left) or large scale cylinder incubators (right). Arctic

rapid access to a renewable source of biological material. Extra attention to growth conditions must nevertheless be paid as most of the secondary metabolites serve as defence mediators and their production may be lowered or stopped when grown in a monoculture without competing species or predators providing a selection pressure. This has previously been shown for the alga Phaeocystis pouchetii, that only upon grazing releases toxic aldehydes to fend off the intruders (Hansen et al. 2004). The "suicide" defence mechanism, triggered by being consumed, of the diatom Thalassiosira rotula is another example (Pohnert 2002) illustrating that carefully combined cultures may be needed to generate biomass that is also containing the desired compounds. The off-shore harvest and large scale in-shore aquaculture of the sponge Lissodendoryx $\mathrm{n}$. sp. to eventually produce $310 \mathrm{mg}$ of halichondrin B illustrate that with sufficient financial support it may also be possible grow relevant marine macroorganisms (Munro et al. 1999; Molinski et al. 2009).

Most of the MabCent pipeline is designed for highthroughput and automation (Luesch 2006). This

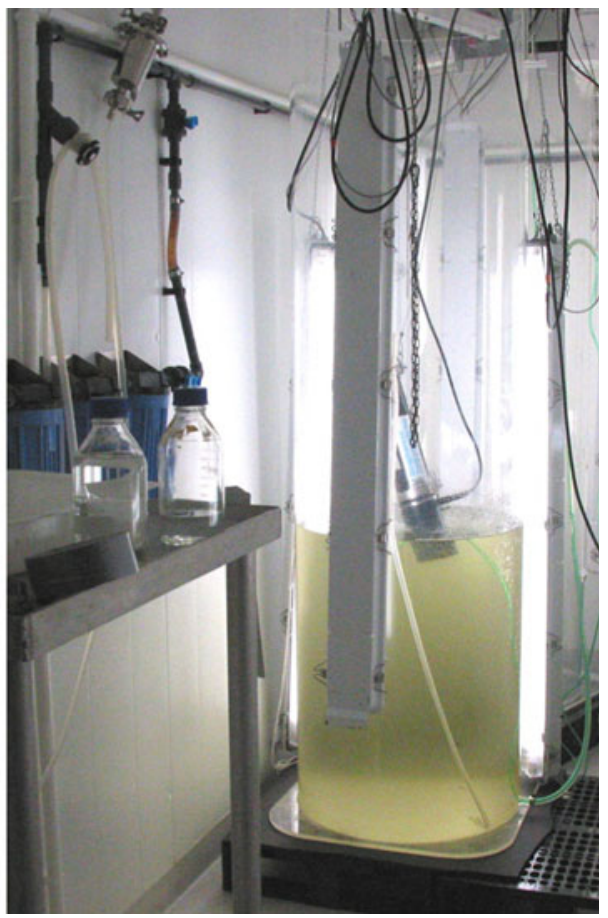

microalgae are flexible and high producing at low light, temperature and nutrition (N\&P). ${ }^{\circ}$ Hans Christian Eilertsen \& Richard Ingebrigtsen UiT

generally works satisfactory for the assays but is less effective for the fractionation process. The challenges associated with high-throughput and natural product extracts are established and several technological improvements are under development (Koehn and Carter 2005). The purification has benefited from applying extra manual manpower and attention to this stage of the process. Ideally each fraction should be followed by a single scientist but that is not a realistic approach given the number of species collected and the timeframes of the project. MabCent is funded for 8 years and its ambition is to screen as many Arctic marine organisms as possible within that period. Such ambitions can only be achieved using a certain degree of high-throughput and automation and it may also potentially mean that some of the low concentration/ high affinity compounds could pass through the system without the attention they need to be discovered. All the data from the screens are however stored and extracts with high potencies but no or low apparent content can be backtracked and re-analysed later once the "lowest hanging fruits" have been studied. 


\section{Outlook}

The MabCent project has now passed halfway and the results of the final 3 years will most likely influence the future direction of research within this field in Norway. The MabCent operation has survived the first difficult years and is now running smoothly and productively and the expectations remain high. With the microorganisms now entering the screening stage there is a general belief that the number of novel compounds will increase.

Several groups at other Norwegian universities have independently started to look into marine bioprospecting and marine chemistry but they are still in the initial start-up phases. Norway is a small country and a national strategy has been developed to generate synergies and make the most of the national resources and competences to allow for future focus on this field.

Acknowledgments MabCent is funded by the Norwegian Research Council (NFR) and its support is greatly acknowledged. Dr. Benjamin Compton and Dr. Espen Hansen are acknowledged for manuscript feedback.

Open Access This article is distributed under the terms of the Creative Commons Attribution License which permits any use, distribution, and reproduction in any medium, provided the original author(s) and the source are credited.

\section{References}

Bohlin L, Goransson U, Alsmark C, Weden C, Backlund A (2010) Natural products in modern life science. Phytochem Rev 9:279-301

Burkholder PR, Pfister RM, Leitz FH (1966) Production of a pyrrole antibiotic by a marine bacterium. Appl Microbiol 14:649-653

Chauhan D, Catley L, Li GL, Podar K, Hideshima T, Velankar M, Mitsiades C, Mitsiades N, Yasui H, Letai A, Ovaa H, Berkers C, Nicholson B, Chao TH, Neuteboom STC, Richardson P, Palladino MA, Anderson KC (2005) A novel orally active proteasome inhibitor induces apoptosis in multiple myeloma cells with mechanisms distinct from Bortezomib. Cancer Cell 8:407-419

Chauhan D, Singh A, Brahmandam M, Podar K, Hideshirna T, Richardson P, Munshi N, Palladino MA, Anderson KC (2008) Combination of proteasome inhibitors bortezomib and NPI-0052 trigger in vivo synergistic cytotoxicity in multiple myeloma. Blood 111:1654-1664

Cragg GM, Grothaus PG, Newman DJ (2009) Impact of natural products on developing new anti-cancer agents. Chem Rev 109:3012-3043

de Backer M, McSweeney S, Rasmussen HB, Riise BW, Lindley P, Hough E (2002) The 1.9 angstrom crystal structure of heat-labile shrimp alkaline phosphatase. J Mol Biol 318:1265-1274

Fenical W, Jensen PR, Palladino MA, Lam KS, Lloyd GK, Potts BC (2009) Discovery and development of the anticancer agent salinosporamide A (NPI-0052). Bioorg Med Chem $17: 2175-2180$

Flaten GE, Kottra G, Stensen W, Isaksen G, Karstad R, Svendsen JS, Daniel H, Svenson J (2011) In vitro characterization of human peptide transporter hPEPT1 interactions and passive permeation studies of short cationic antimicrobial peptides. J Med Chem 54:2422-2432

Garber K (2005) Peptide leads new class of chronic pain drugs. Nat Biotechnol 23:399

Godzik A (2011) Metagenomics and the protein universe. Curr Opin Struct Biol 21:398-403

Gulder TAM, Moore BS (2009) Chasing the treasures of the sea-bacterial marine natural products. Curr Opin Microbiol 12:252-260

Hansen E, Ernstsen A, Eilertsen HC (2004) Isolation and characterisation of a cytotoxic polyunsaturated aldehyde from the marine phytoplankter Phaeocystis pouchetii (Hariot) Lagerheim. Toxicology 199:207-217

Hirata Y, Uemura D (1986) Halichondrins-antitumor polyether macrolides from a marine sponge. Pure Appl Chem 58:701-710

Hopmann KH, Sebestik J, Novotna J, Stensen W, Urbanova M, Svenson J, Svendsen JS, Bour P, Ruud K (2012) Determining the absolute configuration of two marine compounds using vibrational chiroptical spectroscopy. J Org Chem 77:858-869

Imhoff JF, Labes A, Wiese J (2011) Bio-mining the microbial treasures of the ocean: new natural products. Biotechnol Adv 29:468-482

Jensen PR, Fenical W (1994) Strategies for the discovery of secondary metabolites from marine-bacteria-ecological perspectives. Annu Rev Microbiol 48:559-584

Karstad R, Isaksen G, Brandsdal BO, Svendsen JS, Svenson J (2010) Unnatural amino acid side chains as S1, S1 ', and S2 'probes yield cationic antimicrobial peptides with stability toward chymotryptic degradation. J Med Chem 53:55585566

Keck GE, Poudel YB, Cummins TJ, Rudra A, Covel JA (2011) Total synthesis of bryostatin 1. J Am Chem Soc 133: 744-747

Kennedy J, Flemer B, Jackson SA, Lejon DPH, Morrissey JP, O'Gara F, Dobson ADW (2010) Marine metagenomics: new tools for the study and exploitation of marine microbial metabolism. Mar Drugs 8:608-628

Koehn FE, Carter GT (2005) The evolving role of natural products in drug discovery. Nat Rev Drug Discov 4:206-220

König GM, Kehraus S, Seibert SF, Abdel-Lateff A, Muller D (2006) Natural products from marine organisms and their associated microbes. Chem Bio Chem 7:229-238

Kubanek J, Jensen PR, Keifer PA, Sullards MC, Collins DO, Fenical W (2003) Seaweed resistance to microbial attack: a targeted chemical defense against marine fungi. Proc Natl Acad Sci 100:6916-6921

Leiros I, Moe E, Lanes O, Smalas AO, Willassen NP (2003) The structure of uracil-DNA glycosylase from Atlantic cod (Gadus morhua) reveals cold-adaptation features. Acta Crystallogr D 59:1357-1365 
Lidgren G, Bohlin L (1986) Studies of Swedish marine organisms.7. A novel biologically-active indole alkaloid from the sponge Geodia-baretti. Tetrahedron Lett 27:32833284

Litaudon M, Guyot M (1986) Ianthelline, a new derivative of 3,5-dibromo-tyrosine isolated from the sponge Ianthellaardis from the Bahamas I. Tetrahedron Lett 27:4455-4456

Luesch H (2006) Towards high-throughput characterization of small molecule mechanisms of action. Mol BioSyst 2: 609-620

Macherla VR, Liu JN, Sunga M, White DJ, Grodberg J, Teisan S, Lam KS, Potts BCM (2007) Lipoxazolidinones A, B, and $\mathrm{C}$ : antibacterial 4-oxazolidinones from a marine actinomycete isolated from a Guam marine sediment. J Nat Prod 70:1454-1457

Matz C, Webb JS, Schupp PJ, Phang SY, Penesyan A, Egan S, Steinberg P, Kjelleberg S (2008) Marine biofilm bacteria evade eukaryotic predation by targeted chemical defense. PLoS One 3

Mayer AMS, Glaser KB, Cuevas C, Jacobs RS, Kem W, Little RD, McIntosh JM, Newman DJ, Potts BC, Shuster DE (2010) The odyssey of marine pharmaceuticals: a current pipeline perspective. Trends Pharmacol Sci 31:255265

Mayer AMS, Rodriguez AD, Berlinck RGS, Fusetani N (2011) Marine pharmacology in 2007-8: marine compounds with antibacterial, anticoagulant, antifungal, anti-inflammatory, antimalarial, antiprotozoal, antituberculosis, and antiviral activities; affecting the immune and nervous system, and other miscellaneous mechanisms of action. Comp Biochem Phys C 153:191-222

Moellering RC (2003) Linezolid: the first oxazolidinone antimicrobial. Ann Int Med 138:135-142

Molinski TF, Dalisay DS, Lievens SL, Saludes JP (2009) Drug development from marine natural products. Nat Rev Drug Discov 8:69-85

Munro MHG, Blunt JW, Dumdei EJ, Hickford SJH, Lill RE, Li SX, Battershill CN, Duckworth AR (1999) The discovery and development of marine compounds with pharmaceutical potential. J Biotechnol 70:15-25

Mutter R, Wills M (2000) Chemistry and clinical biology of the bryostatins. Bioorg Med Chem 8:1841-1860

Olivera BM, Gray WR, Zeikus R, McIntosh JM, Varga J, Rivier J, Desantos V, Cruz LJ (1985) Peptide neurotoxins from fish-hunting cone snails. Science 230:1338-1343

Pettit GR, Herald CL, Doubek DL, Herald DL, Arnold E, Clardy J (1982) Anti-neoplastic agents.86. Isolation and structure of bryostatin-1. J Am Chem Soc 104:6846-6848
Pettit GR, Tan R, Gao F, Williams MD, Doubek DL, Boyd MR, Schmidt JM, Chapuis JC, Hamel E, Bai R, Hooper JNA, Tackett LP (1993) Isolation and structure of halistatin-1 from the eastern Indian-ocean marine sponge Phakelliacarteri. J Org Chem 58:2538-2543

Pohnert G (2002) Phospholipase A(2) activity triggers the wound-activated chemical defense in the diatom Thalassiosira rotula. Plant Physiol 129:103-111

Rosenfeld WD, ZoBell CE (1947) Antibiotic production by marine microorganisms. J Bacteriol 54:393-398

Schaufelberger DE, Koleck MP, Beutler JA, Vatakis AM, Alvarado AB, Andrews P, Marzo LV, Muschik GM, Roach J, Ross JT, Lebherz WB, Reeves MP, Eberwein RM, Rodgers LL, Testerman RP, Snader KM, Forenza S (1991) The large-scale isolation of bryostatin-1 from Bugulaneritina following current good manufacturing practices. J Nat Prod 54:1265-1270

Simon C, Daniel R (2011) Metagenomic analyses: past and future trends. Appl Environ Microb 77:1153-1161

Smalas AO, Leiros HKS, Os V, Willassen NP (2000) Cold adapted enzymes. In: El-Gewely MR (ed) Biotechnology annual review, vol 6. Elsevier, Amsterdam, pp 1-57

Sudek S, Lopanik NB, Waggoner LE, Hildebrand M, Anderson C, Liu HB, Patel A, Sherman DH, Haygood MG (2007) Identification of the putative bryostatin polyketide synthase gene cluster from "Candidatus endobugula sertula", the uncultivated microbial symbiont of the marine bryozoan Bugula neritina. J Nat Prod 70:67-74

Svenson J, Stensen W, Brandsdal BO, Haug BE, Monrad J, Svendsen JS (2008) Antimicrobial peptides with stability toward tryptic degradation. Biochemistry 47:3777-3788

Tadesse M, Strom MB, Svenson J, Jaspars M, Milne BF, Torfoss V, Andersen JH, Hansen E, Stensvag K, Haug T (2010) Synoxazolidinones A and B: novel bioactive alkaloids from the ascidian Synoicum pulmonaria. Org Lett 12:4752-4755

Tadesse M, Svenson J, Jaspars M, Strom MB, Abdelrahman MH, Andersen JH, Hansen E, Kristiansen PE, Stensvag K, Haug T (2011a) Synoxazolidinone C; a bicyclic member of the synoxazolidinone family with antibacterial and anticancer activities. Tetrahedron Lett 52:1804-1806

Tadesse M, Tabudravu JN, Jaspars M, Strom MB, Hansen E, Andersen JH, Kristiansen PE, Haug T (2011b) The antibacterial ent-eusynstyelamide B and eusynstyelamides D, $\mathrm{E}$, and $\mathrm{F}$ from the Arctic bryozoan Tegella cf. spitzbergensis. J Nat Prod 74:837-841

Terlau H, Olivera BM (2004) Conus venoms: a rich source of novel ion channel-targeted peptides. Physiol Rev 84:41-68 